on the State Fair grounds this month to be used in the kitchen. It was found that waste, stale meat thrown into a box was more attraotive to the flies than bread and milk in the trap. This was overcome by putting small pieces of the stale meat in the pans with the bread and milk and the receptacle of the trap was soon swarming with thousands of flies.

The flies, which gather in the upper part or receptacle, should be killed by immersing that part of the trap in hot water or pouring boiling water over it, or in any other way not injurious to the trap. The dead flies may be emptied out of the trap, the bait renewed and the trap reset.

We have been so pleased with the success of this contrivance that we have proposed for it the name which is used at the head of this article.

\title{
ARTHROCNODAX OCCIDENTALIS N. SP. (DIPT.)
}

By E. P. FeLt, Albany, N. Y.

The small, yellowish species described below and easily separated from other American forms by the emarginate ventral plate, was reared July 15 and 30,1912 , by H. J. Quayle of the Division of Entomology, University of California, Berkeley, from larvæ preying on red spiders, Tetranychus species.

Male. Length $1 \mathrm{~mm}$. Antennae a little longer than the body, thickly haired, pale straw, yellowish basally; 14 segments, the fifth having the stems with a length 2 1-2 and 3 1-2 times their diameters. Palpi; the first segment short, irregular, the second with a length over twice its width, the third 1-2 longer than the second, the fourth a little longer than the third, slender. Mesonotum fuscous yellowish. Scutellum and postscutellum yellowish. Abdomen pale yellowish, with a reddish orange spot basally. Halteres yellowish transparent. Wings hyaline. Legs mostly pale straw, the distal tarsal segments somewhat darker; claws slender, evenly curved, the pulvilli as long as the claws. Genitalia fuscous yellowish, both dorsal and ventral plates triangularly emarginate, each with the lobes sparsely setose apically. Type a 2328. 